\section{Commentary: Do you get what you pay for when it's free?}

\author{
Gaetano Paone, MD, MHSA
}

It is now more than 3 decades since Loop and colleagues ${ }^{1}$ first reported improved survival when using the internal mammary artery (IMA) to bypass the left anterior descending artery (LAD). In this issue of the Journal, Marzouk and colleagues ${ }^{2}$ address one approach to conduit choice for additional grafts by comparing long-term outcomes with an in situ versus a free IMA graft as a second arterial conduit.

Of 23,249 patients undergoing isolated coronary bypass grafting from 1992 to 2017, 2600 patients received bilateral internal mammary arteries (BIMAs) specifically with an in situ IMA graft (left IMA in $~ 90 \%$ ) to the LAD. In 2464 of these, both IMAs were used as in situ grafts. In the remaining 136 patients $(5.2 \%)$, the second IMA was used as a free graft to non-LAD targets, with additional use of radial artery and saphenous vein conduits as appropriate. Shortterm outcomes including operative mortality were similar. However, with mean follow-up of $11.7 \pm 7.1$ years, patients receiving BIMA in situ grafts had better long-term survival and freedom from cardiovascular mortality at 5-, 10-, and 15 -year periods, despite readmission for cardiac indications and revascularization being similar for both groups.

The one-to-many matching algorithm accounts only for preoperative variables. Angiographic confirmation of graft status is lacking, thereby not accounting for the conduit itself, the size, and quality of the coronary target and technical aspects, including the additional proximal anastomosis-all important in influencing long-term graft patency. It is therefore not possible to determine to what

From the Structural Heart and Valve Center, Division of Cardiothoracic Surgery, Emory University School of Medicine, Atlanta, Ga.

Disclosures: Author has nothing to disclose with regard to commercial support.

Received for publication March 20, 2020; revisions received March 20, 2020; accepted for publication March 20, 2020; available ahead of print April 6, 2020.

Address for reprints: Gaetano Paone, MD, MHSA, Structural Heart and Valve Center,

Division of Cardiothoracic Surgery, Emory University Midtown Hospital, 550

Peachtree St, NE, Davis-Fischer Bldg, 4th floor, Atlanta, GA 30308 (E-mail: gaetano.paone@emory.edu).

J Thorac Cardiovasc Surg 2021;162:1754-5

$0022-5223 / \$ 36.00$

Copyright (c) 2020 by The American Association for Thoracic Surgery

https://doi.org/10.1016/j.jtcvs.2020.03.079

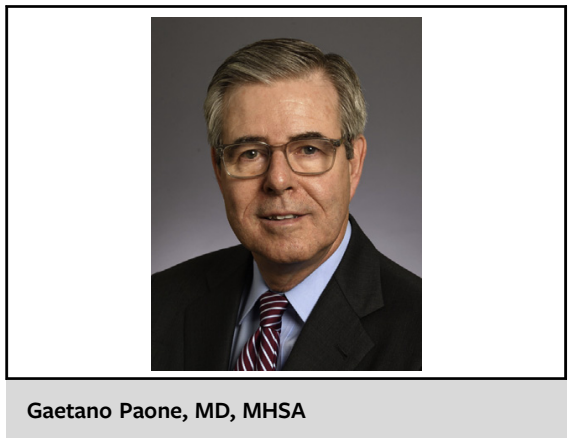

CENTRAL MESSAGE

The free IMA graft should be considered a viable alternative second arterial conduit when in situ use is not feasible.

extent the fate of the free IMA graft may be responsible for the demonstrated differences in outcome.

The take-home message states that "Preserving the integrity of the second IMA optimizes the long-term survival associated with the BIMA." Essentially all of the 136 free grafts in the study were used only when circumstances like harvest injury or inadequate length precluded intended use as in situ graft. This suggests the surgeons, when using a second IMA graft, did indeed make every effort to do so as an in situ conduit. Although not addressed by this analysis, the more relevant comparison may be between use of a free IMA graft versus saphenous vein and/or radial artery grafts for additional non-LAD targets.

There are certainly understandable, particularly technical reasons, why outcomes may somewhat favor in situ versus free grafts. Previous work, however, including from the authors, has demonstrated comparable outcomes when using free IMA grafts, including to bypass the LAD. ${ }^{3-5}$ Why then should outcomes be worse when using a free graft to bypass presumably less critical targets?

The study is well done; however, the small number of free grafts over this protracted time frame with great heterogeneity in both the reason and the manner in which they were used limits the value of any comparisons. The results, therefore, should not be interpreted to suggest inferiority of the free IMA as a bypass conduit, and the authors were appropriately cautious not to conclude that use of the free IMA as a second arterial graft should be avoided. Free should refer to the graft technique, not its value. 


\section{References}

1. Loop FD, Lytle BW, Cosgrove DM, Stewart RW, Goormastic M, Williams GW, et al. Influence of the internal-mammary-artery graft on 10-year survival and other cardiac events. N Engl J Med. 1986;314:1-6.

2. Marzouk M, Kalavrouziotis D, Grazioli V, Meneas C, Nader J, Simard S, et al. Long-term outcome of the in situ versus free internal thoracic artery as the second arterial graft. J Thorac Cardiovasc Surg. 2021;162: 1744-52.e7.
3. Vistarini N, Kalavrouziotis D, Dagenais F, Dumont E, Voisine P, Mohammadi S Does the use of a free internal mammary artery graft on the left anterior descending artery compromise long-term survival? Eur J Cardiothorac Surg. 2017;52:753-9.

4. Tatoulis J, Buxton BF, Fuller JA. The right internal thoracic artery: the forgotten conduit—5,766 patients and 991 angiograms. Ann Thorac Surg. 2011;92:9-17.

5. Assi R, Youssef SJ, Almarzooq Z, Al-Raweshidy Y, Hashim PW, Geirsson A, et al. The "free" right internal thoracic artery: a versatile and durable conduit. J Card Surg. 2014;29:609-15
See Article page 1744 .

\section{Commentary: To BIMA or not to BIMA, that should be the question, rather than how to BIMA}

\author{
Thomas A. Schwann, MD, MBA, and \\ Mario F. L. Gaudino, MD ${ }^{\mathrm{b}}$
}

Observational studies uniformly report the benefits of bilateral internal mammary artery (BIMA) grafting, ${ }^{1,2}$ yet the only randomized trial did not corroborate these benefits. ${ }^{3}$ Not surprisingly, there is skepticism regarding BIMA grafting, and its adoption remains at less than 5\% among patients who undergo coronary artery bypass grafting (CABG). ${ }^{4}$ Marzouk and colleagues ${ }^{5}$ compare outcomes between patients whose second internal mammary artery was either used as an situ (is-BIMA) or as a free (f-BIMA) graft. Among their highly selected ( $12 \%$ of entire CABG population) young and healthy CABG cohort, $2464(95 \%)$ isBIMA patients were compared with $136(5 \%)$ f-BIMA patients. The authors found that f-BIMA was associated with significantly increased risk of long-term mortality but with similar hospital readmission and repeat revascularization rates. Significantly, despite the young age and absence of comorbidities, the mediastinitis rate was disturbingly high; $2.5 \%$ vs $1.08 \%$ reported for CABG patients in the Society of Thoracic Surgeons database ${ }^{6}$.

These results have to be considered cautiously despite the commendable statistical risk adjustment. The investigators

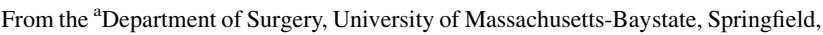
Mass; and ${ }^{\mathrm{b}}$ Department of Cardiothoracic Surgery, Weill-Cornell Medical College, New York, NY.

Disclosures: Authors have nothing to disclose with regard to commercial support. Received for publication March 11, 2020; revisions received March 11, 2020; accepted for publication March 13, 2020; available ahead of print April 5, 2020. Address for reprints: Thomas A. Schwann, MD, MBA, 759 Chestnut St, Springfield, MA 01199 (E-mail: Thomas.schwannMD@baystatehealth.org or taschwann@ gmail.com).

J Thorac Cardiovasc Surg 2021;162:1755-6

$0022-5223 / \$ 36.00$

Copyright (C) 2020 by The American Association for Thoracic Surgery

https://doi.org/10.1016/j.jtcvs.2020.03.063
}

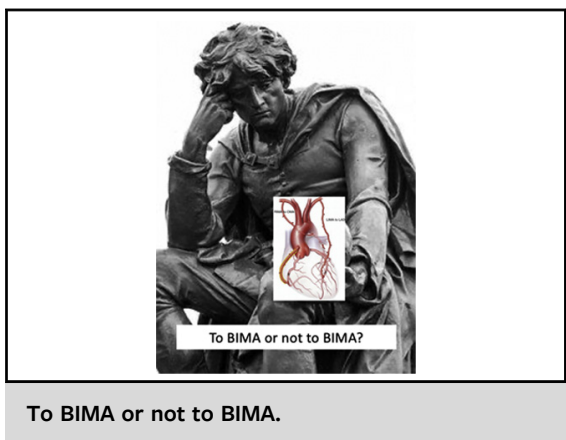

CENTRAL MESSAGE

BIMA grafting will remain a niche, rather than a routine, procedure pending convincing randomized data.

postulate that the increased f-BIMA mortality risk may be due to a greater failure rate of the f-BIMA versus is-BIMA. Although possible, given the additional anastamosis inherent to f-BIMA, this hypothesis is difficult to reconcile without an accompanying increase in hospitalization or repeat revascularization rates, which would be expected if worse f-BIMA durability was the culprit. Recognizing this conundrum, the authors further posit that f-BIMA failure may result in sudden cardiac death which would not increase the hospitalization or repart recvascularization rates. That seems implausible, given the findings of the PREVENT IV (Project of Ex-vivo Vein Graft Engineering via Transfection) trial, ${ }^{7}$ in which graft failure was associated with increased repeat revascularization rates but not increased mortality. Moreover, a number of reports document excellent free IMA patency. ${ }^{8,9}$ Thus, we are left without a credible basis for the main finding of the study.

This study is unfortunately not likely to change surgeons' practice patterns or impact their views of the value of BIMA grafting. To move the BIMA utilization needle will require convincing randomized data, and the only such trial ${ }^{10}$ is still years away. Short of that, BIMA grafting will likely remain 